\title{
Ultrapathological evaluation of the anticancer effect of blackseed (Nigella sativa) and garlic (Allium sativum) in mice
}

\author{
Wael Gamal Nouh \\ Department of Pathology, Faculty \\ of Veterinary Medicine, Zagazig \\ University, Zagazig, Egypt; Department \\ of Medical Laboratories, Faculty of \\ Community, King Khaled University, \\ El Namas, Saudi Arabia
}

\begin{abstract}
In this experimental work, 120 virgin female mice (body weight $40 \pm 10 \mathrm{gm}$ ) were divided into 6 equal groups. Mice in Group 1 served as a control. Mice in Groups 2 and 3 were fed on a basal diet provided with $100 \mathrm{mg} / \mathrm{kg}$ b.wt from each of blackseed (Nigella sativa) and garlic (Allium sativum), respectively, for one month. Mice in Group 4 were inoculated subcutanously $(\mathrm{S} / \mathrm{C})$ with Ehrlich tumor cells after one month from the start of the experiment. Mice in Groups 5 and 6 were treated similarly to those in Groups 3 and 4, respectively, for one month and then immediately inoculated S/C with Ehrlich tumor cells (ETC, $0.1 \mathrm{~mL} /$ mouse). Blood samples were taken from mice of Groups 1,2 and 3 at one month of experiment and tissue specimens were collected from mice in all groups two weeks after inoculation of Ehrlich tumor cells. Histopathologically, Groups 2 and 3 showed proliferation of mononuclear phagocytic system and mild degeneration of internal organs. In Group 4, histopathology revealed neoplastic mass with signs of malignancy, ultrastructurely exhibited pleomorphism, degenerated organelles with activated euoand heterochromatin and cavitations of the cytoplasm. Groups 5 and 6 revealed much smaller neoplastic growth with necrosis and hemorrhage. The necrotic neoplastic cells replaced by empty cavities with congested blood vessels, the others showed pyknotic or karryolytic nuclei. In Groups 5 and 6, the electron microsopic appearance of the neoplastic growth exhibited degenerated and swollen cells with multiple cavitations. Most of the cytoplasmic organelles were degenerated with activation of lysozymes. It could be concluded that, both garlic and black seed minimize the histopathological and electron microscopic alterations of ETC in mice.
\end{abstract}

Cancer has become an important topic in medicine since it is a major cause of death in both the developed and developing countries, and is now only secondary to that of myocardial infarction. ${ }^{1}$ A great majority of human cancers (approx. 80-90\%) are attributable to environmental factors. However, it is not an easy task to eliminate carcinogenic causes from the environment. While modern surgery has significantly reduced cancer mortality, the use of additional treatment such as radiotherapy and chemotherapy has resulted in no more than a $5 \%$ reduction in the number of deaths. ${ }^{2}$ Therefore, there is a continuing search for better control and preventive methods in order to reduce cancer mortality and related side effects. Many investigations are now being carried out to discover naturally occurring compounds which can suppress or prevent the process of carcinogenesis. ${ }^{3,4}$

Epidemiological studies continue to support the premise that dietary intake of Allium vegetables such as garlic may reduce the risk of different types of malignancies, included tumors of the liver, ${ }^{5}$ lung, ${ }^{6}$ skin, ${ }^{7}$ stomach in rodents. ${ }^{8}$ The protective effect against cancer of Allium vegetables is attributed to organosulfur compounds (OSC) including diallyl sulfide, diallyl disulfide (DADS), and/or diallyl trisulfide (DATS).These compounds have an immunomodulatory effect. ${ }^{9}$

Nigella sativa L. (Ranunculaceae family) seeds, commonly known as blackseed or black cumin, have been used for thousands of years as a spice and food preservative, as well as a protective and curative remedy for numerous disorders. ${ }^{10}$ The pharmacological investigations of the seed extracts reveal a broad spectrum of activities including immunopotentiation, 11 anti-diabetic, 12 anti-hypertensive, ${ }^{13}$ anti-inflammatory and anti-microbial action. 14 Many of these activities have been attributed to the quinone constituents of the seed. 15

The present study aimed to evaluate the anti-cancer effect of Nigella sativa and garlic (Allium sativum) against Ehrlich tumor cells by monitoring the hematologic, immunological, histopathological and electron microscopic findings.

\section{Materials and Methods}

\section{Mice}

One hundred and twenty virgin female mice (body weight $40 \pm 10 \mathrm{gm}$ ) were brought from Fac. Vet. Med., Zagazig University, Egypt. Mice were divided into 6 equal groups and reared in metal cages under hygienic conditions, main-
Correspondence: Wael Gamal Nouh, Department of Pathology, Faculty of Veterinary Medicine, Zagazig University, Zagazig, Egypt.

Tel. +20.1068384900 - Fax: +20.552283683

E-mail: wael131269@yahoo.com

Key words: ultrapathological, anticancer, blackseed, garlic.

Conflict of interests: the author declares no potential conflict of interests.

Received for publication: 14 December 2012.

Revision received: 18 February 2013.

Accepted for publication: 20 February 2013.

This work is licensed under a Creative Commons Attribution NonCommercial 3.0 License (CC BYNC 3.0).

(C) Copyright W.G. Nouh, 2013

Licensee PAGEPress srl, Italy

Veterinary Science Development 2013; 3:e3 doi:10.4081/vsd.2013.e3

tained on a balanced diet, and provided with tap water for the entire study period.

\section{Immunostimulants}

Both blackseed and garlic were obtained from Medical Pharmacy and provided to selected groups of the experimented mice orally on a daily basis for 30 days consecutively with a dose of $100 \mathrm{mg} / \mathrm{kg}$ b.wt. for each of blackseed (Nigella sativa) and garlic (Allium sativum).

\section{Ehrlich tumor cells}

Ehrlich tumor cells were taken from tumor cell lines cultured in National Cancer Institute, Cairo University, Egypt. The tumor cells were diluted with normal saline in a ratio of $1: 3$, then injected subcutanously (S/C) to experimented mice in a dose of $0.1 \mathrm{~mL} /$ mouse where each $0.1 \mathrm{~mL}$ contain 1 million tumor cells.

\section{Experiment}

Mice in Group 1 served as control for the entire study period. Mice in Groups 2 and 3 were fed on a basal diet provided with 100 $\mathrm{mg} / \mathrm{kg}$ b. wt. from blackseed (Nigella sativa) and $100 \mathrm{mg} / \mathrm{kg}$ b.wt from garlic (Allium sativum), respectively, for one month. Mice in Group 4 were inoculated S/C with Ehrlich tumor cells $(0.1 \mathrm{~mL} / \mathrm{mouse}$ where each $0.1 \mathrm{~mL}$ contain 1 million tumor cells) one month after the study start. Mice in Groups 5 and 6 were fed on a basal diet provided with $100 \mathrm{mg} / \mathrm{kg}$ b.wt from blackseed (Nigella sativa) and 100 $\mathrm{mg} / \mathrm{kg}$ b.wt from garlic (Allium sativum), respectively, for one month and then immediately inoculated $\mathrm{S} / \mathrm{C}$ with Ehrlich tumor cells $(0.1 \mathrm{~mL} /$ mouse where each $0.1 \mathrm{~mL}$ contain 1 million tumor cells). 


\section{Sampling}

Blood and tissue specimens were taken from mice of Groups 1, 2 and 3 at one month from study start and tissue specimens were collected from mice in Groups 1, 4, 5 and 6 at two weeks from Ehrlich tumor cell inoculation.

\section{Parameters measured}

i) Total and differential leukocyte counts were performed in triplicate for each sample according to Feldman et al. ${ }^{16}$

ii) GSH and Malnoaldhyde (MDA) of blood RBCs were measured spectrophotometerically. GSH is determined by colorimetric method by ready-made kits provided by Bio-diagnostic, Egypt, according to the manufacturer's instructions. GSH determination was based on the reduction of 5.5 - dithiobis (2-nitrobenzoic acid) (DTNB) with GSH to produce a yellow compound. The reduced chromogen is directly proportional to GSH concentration and its absorbance can be measured at $405 \mathrm{~nm}$.

MDA is determined by colorimetric method by ready-made kits provided by Bio-diagnostic, Egypt, according to the manufacturer's instructions. Thiobarbituric acid (TBA) reacts with MDA in acidic medium at $95^{\circ} \mathrm{C}$ for $30 \mathrm{~min}$ to form TBA reactive product, and the absorbance of the resultant pink product can be measured at $534 \mathrm{~nm}$.

iii) Serum lysozyme was determined by the turbidometric assay. Briefly, the lysozyme substrate was $0.75 \mathrm{mg} / \mathrm{mL}$ of gram positive bacterium Micrococcus lysodeikticus lyophilized cells (Sigma, St. Louis, M0, USA). The substrate was suspended in $0.1 \mathrm{M}$ sodium phosphate/citric acid buffer, pH 5.8. Plasma: 25 L were placed in triplicate into a microtiter plate and $175 \mathrm{l}$ of substrate solution was added to each well at $25^{\circ} \mathrm{C}$. The reduction in absorbance at $450 \mathrm{~nm}$ was read after 0 and 20 min using microplate ELISA reader (Bio TEC, ELX800G,

Table 1. Some hematologic and immunological parameters of mice provided with a dose of $100 \mathrm{mg} / \mathrm{kg}$ b.wt. for each of blackseed (Nigella sativa) and garlic (Allium sativum) for one month in comparison to control (mean \pm standard error).

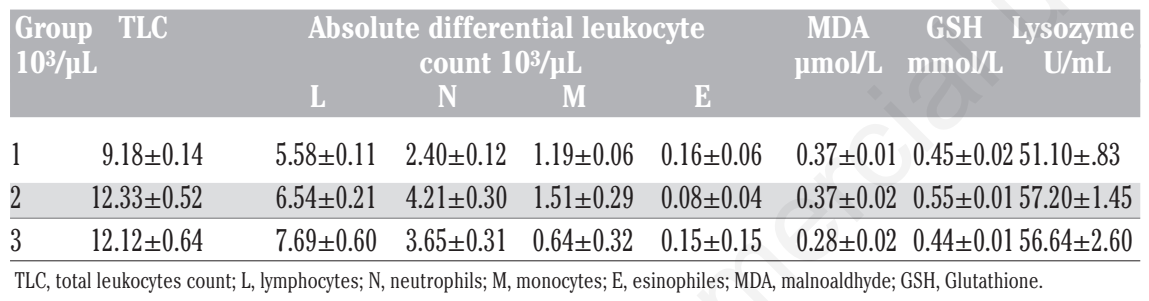

Table 2. Histopathological score of mice provided with a dose of $100 \mathrm{mg} / \mathrm{kg} \mathrm{b.wt}$. for each of blackseed (Nigella sativa) and garlic (Allium sativum) for one month in comparison to the control.

\begin{tabular}{lccc}
\hline Findlings & & Groups & \\
& 1 & 2 & 3 \\
Activation of Kupffer's cells & - & ++ & ++ \\
Proliferation of mesangial cells & - & + & + \\
\hline Proliferation of lymphocytes in the white pulp & - & +++ & ++ \\
\hline- , normal; +, mild; ++, moderate; +++, severe; ++++, intensely severe. & &
\end{tabular}

Table 3. Scoring of histopathological and electron microscopic findings of mice provided with a dose of $100 \mathrm{mg} / \mathrm{kg}$ b.wt. for each of blackseed (Nigella sativa) and garlic (Allium sativum) for one month and inoculated S/C with ETC in comparison to mice inoculated S/C with ETC alone.

\begin{tabular}{lccc} 
Findings & \multicolumn{3}{c}{ Groups } \\
& 4 & 5 & 6 \\
Neoplastic mass & ++++ & ++ & + \\
\hline Pleomorphic cell & ++++ & ++ & + \\
Hyperchromatic nuclei & ++++ & ++ & + \\
\hline Degenerated cytoplasmic organelles & ++++ & ++ & +++ \\
Lysozyme activities & ++ & +++ & +++ \\
Degeneration and necrosis of neoplastic cell & + & ++ & + \\
Neoplastic cell proliferation & ++++ & ++ & +
\end{tabular}
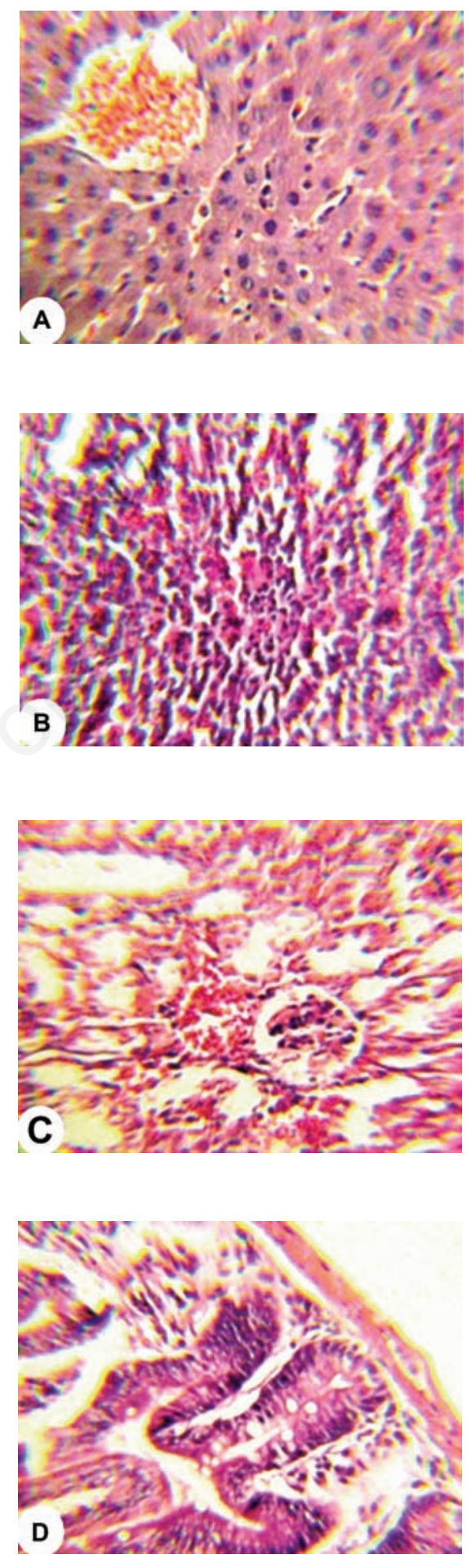

Figure 1. A) Liver of mice one month after study start showing focal vacuolar degeneration in the hepatocytes and activation of Kupffer's cells; B) spleen of mice one month after study start showing active proliferation of lymphocytes in the white pulp; C) kidney of mice one month after study start showing mild tubular nephrosis and proliferation of mesangial cells; D) intestine of mice one month after study start showing some mononuclear cell infiltrations in the lamina propria. (Haematoxylin \& Eosin x250). 
USA). The units of lysozyme present in serum $(\mu \mathrm{g} / \mathrm{mL})$ were obtained from standard curve made with lyophilized hen-egg-white-lysozyme (Sigma).

iv) Histopathology: tissue specimens from the liver, lung, kidney, intestine and spleen of the mice were fixed in $10 \%$ phosphate buffer formalin, processed routinely and blocked in paraffin. Then, five micron thick paraffin sections were prepared and stained with hematoxylin and eosin, (H\&E). ${ }^{17}$

v) Electron microscopy: selected lesions from neoplasitic mass were fixed in $2.5 \%$ glutraldehyde followed by $1 \%$ osmium tetroxide. Dehydration was carried out in ethanol using poly-ethylene capsules containing the embedding mixture (Epon mixture and hardener). Ultrathin sections were cut and stained by uranyl acetate and lead citrate. 18

\section{Statistical analyses}

One-way ANOVA was used to evaluate the significant difference of the different treatments and duration. $\mathrm{P} \leq 0.05$ was considered significant. Means and standard errors were also estimated. The SAS program was used for all statistical analyses. ${ }^{19}$

\section{Results}

The results of this study are presented in Tables 1-3 and Figures 1-5.

\section{Hematological and immunological findings}

Table 1 illustrates a significant increase in total leukocyte count, lymphocytes, neutrophils, and lysozyme in Group 2 (Nigella sati$v a$ ) and Group 3 (garlic) of experimental mice. GSH significantly increased in Group 2 while Malnoaldhyde (MDA) had the same value in Group 2 (Nigella sativa) and non-significant decrease in Group 3 (garlic).

\section{Histopathological and electron microscopic results}

Clinically, the mice of Groups 1, 2 and 3 showed normal posture (back slightly arched when sitting) and mobility (agile with stretched back) reactions to stimuli (sound, light, smell), with exploratory behavior and self-grooming with their teeth and claws. The mice of Group 4 were lethargic, depressed, with reduced self-grooming and problems of mobility while the mice of Groups 5 and 6 showed relatively improved activity.

The tumors induced by ETC inoculation at the site of injection were very prominent, nodular and revealed fast growth (Group 4) while Groups 5 and 6 showed a relatively smaller and slower tumor growth compared to Group 4. The central area of the tumor was depressed and necrotic in Group 4 while extensive areas of atrophy and necrosis on the tumor growth were seen in Groups 5 and 6 .

In Group 1 (control group), the internal organs of the experimented mice showed no prominent histopathological changes.

In Group 2 (Blackseed, Nigella sativa), the liver showed focal vacuolar degeneration in the hepatocytes and activation of Kupffer's cells (Figure 1A). The lung was congested and infiltrated with mononuclear leukocytes. The kidneys revealed congestion, tubular nephrosis and proliferation of mesangial cells. The intestine exhibited mucinous degeneration in the epithelial lining, and some mononuclear cell infiltrations in the lamina propria and submucosa. The spleen showed active proliferation of lymphocytes in the white pulp (Figure 1B).

In Group 3 (Garlic, Allium sativum), the liver showed dilatation of central vein with mild swelling in the hepatocytes and activation of Kupffer's cells. The lung was infiltrated with mononuclear leukocytes. The kidneys revealed mild tubular nephrosis and proliferation of mesangial cells (Figure 1C). The intestine showed some mononuclear cell infiltrations in
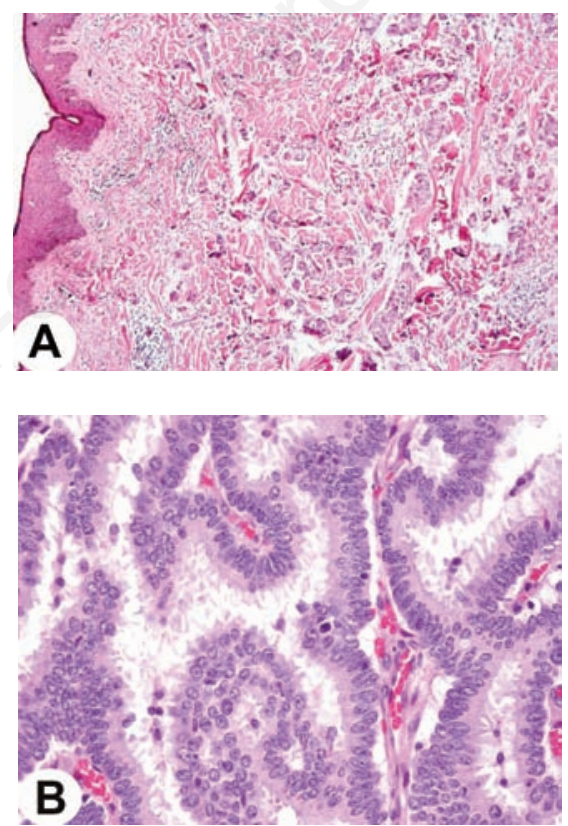

Figure 2. Neoplastic mass of mice at two weeks post inoculation showing: A) numerous tumor cells that showed excessive proliferation, large size with signs of malignancy, and mostly ovoid to polyhedral in shape (Haematoxylin \& Eosin $\mathrm{x} 250$ ); B) congestion, hemorrhage in the stroma and cells containing hyperchromatic nuclei with typical and atypical mitotic figures (Haematoxylin \& Eosin $\mathrm{x} 400$ ).
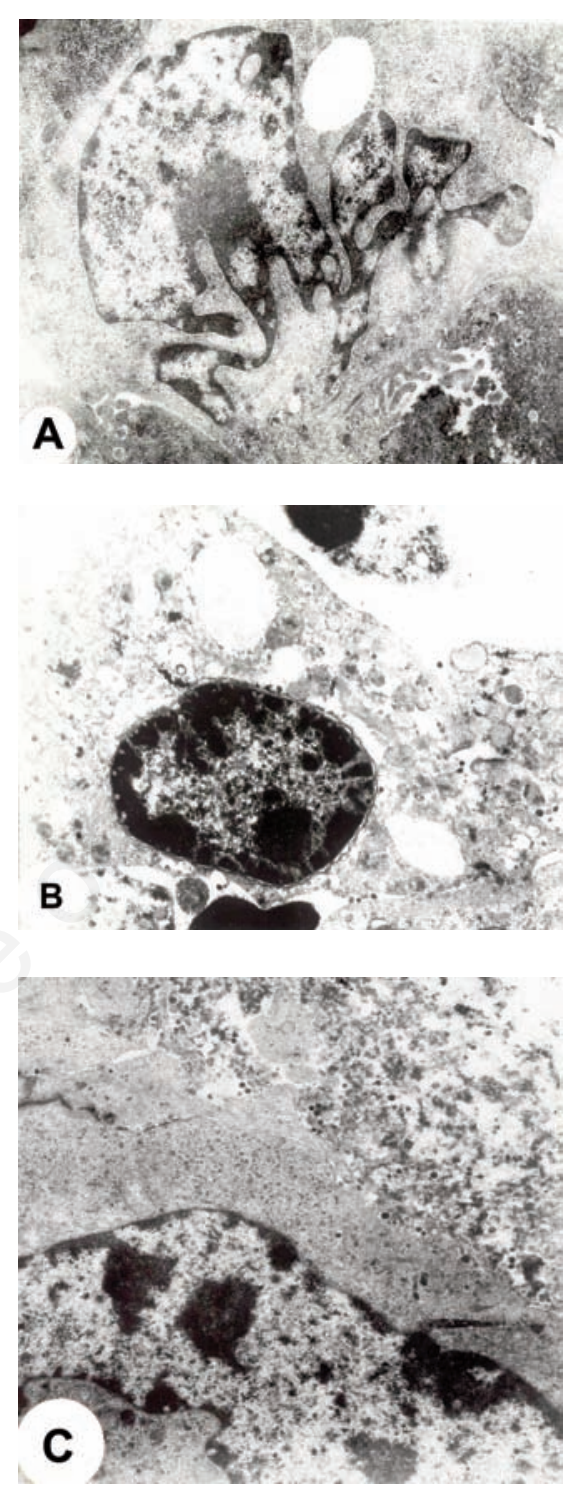

Figure 3. A) The ultrastructural of the neoplastic growth, of mice at two weeks post inoculation showing pleomorphic cell with pleomorphic hyperchromatic nuclei that showed activated euo- and heterochromatin with cavitations of the cytoplasm and dispersed glycogen granules. Most of the cytoplasmic organelles were degenerated. B) Neoplastic growth at utrastructural level of mice fed on blackseed and inoculated with ETC at two weeks post-inoculation showing degenerated and swollen cells. The mitochondria and endoplasmic reticulum were swollen. Other cytoplasmic organelles were degenerated and appeared homogenous, especially those around the nuclei. The nucleus showed condensation of both heterochromatin and euochromatin. C) The electron microsopic appearance of the neoplastic growth of mice fed on garlic and inoculated with ETC at two weeks post inoculation showing multiple cavitation within the cytoplasm with pyknotic nuclei that exhibited condensed chromatin. The majority of the cytoplasmic organelles were degenerated and necrotic. Uranely acetate and lead citrate, magnification $45,000 x$. 
the lamina propria (Figure 1D). The spleen showed focal proliferation of lymphocytes in the white pulp.

In Group 4 (Ehrlich tumor cells), the histopathology of the neoplastic mass consisted of numerous tumor cells that exhibited excessive proliferation, a large size with signs of malignancy. The cells were varied in shape and size and mostly ovoid to polyhedral in shape (Figure 2A). The neoplastic mass showed congested blood vessels and focal hemorrhage in the stroma. The cells contained hyperchromatic nuclei with typical and a typical mitotic figures (Figure 2B). The center of the neoplastic mass contained some degenerated vacuolated cells of weak staining affinity. The ultrastructural studies of the neoplastic growth exhibited pleomorphic cell with pleomorphic hyperchromatic nuclei that showed activated euo- and heterochromatin. Cavitation of the cytoplasm was common with the glycogen granules dispersed within the cytoplasm. Most of the cytoplasmic organelles were degenerated and the mitochondria swollen. Lysozyme activities were also observed (Figure 3A).
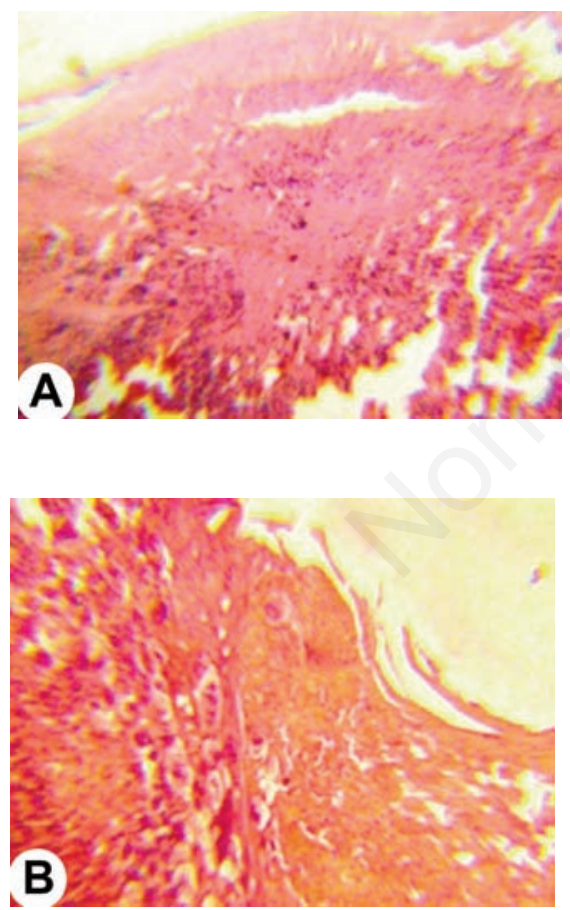

Figure 4. Neoplasitic mass of mice fed on blackseed and inoculated with ETC at two weeks post inoculation showing: A) degenerated cells and widespread necrosis and focal hemorrhage among the neoplastic tissue; B) necrotic neoplastic cells and empty cavities with congested blood vessels, focal hemorrhage. (Haematoxylin \& Eosin x250).

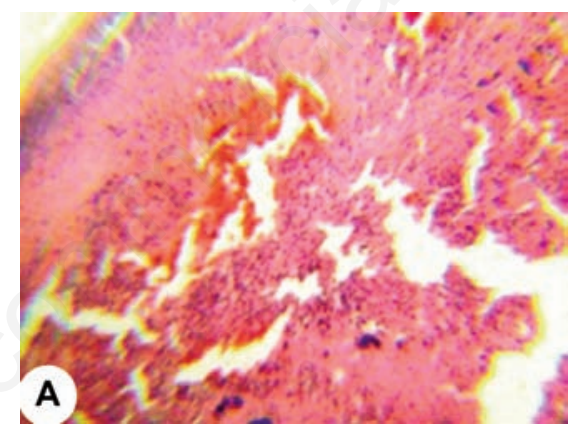

In Group 5, (Blackseed, Nigella sativa + Ehrlich tumor cells), the microscopic finding of the neoplasitic mass lacked the characteristic architecture and appeared to be much smaller. The majority of the neoplastic cells were degenerated and lost their nuclei. Also, widespread necrosis and focal hemorrhage were found among the neoplastic tissue (Figure 4A). The necrotic neoplastic cells were replaced by empty cavities with congested blood vessels, focal hemorrhage, while others showed pyknotic or karryolytic nuclei (Figure 4B).

The electron microsopic appearance of the neoplastic growth showed degenerated and swollen cells. The glycogen granules were dispersed and restricted toward the extremity of the cell. The mitochondria and endoplasmic reticulum were swollen, other cytoplasmic organelles were degenerated and appeared homogenous, especially those around the nuclei. The nucleus showed condensation of both heterochromatin and euochromatin (Figure 3B).

In Group 6, (Garlic, Allium sativum + Ehrlich tumor cells), the light microscopic picture of the neoplastic mass consisted of a compara-

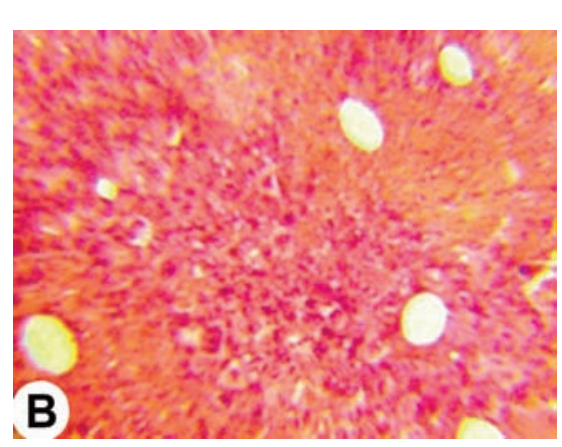

Figure 5. Neoplasitic mass of mice fed on garlic and inoculated with ETC at two weeks post inoculation showing: A) lower number of tumor cells that presented signs of degeneration and necrosis; B) focal to diffuse areas of necrosis with empty cavities and focal to diffuse hemorrhage. (Haematoxylin \& Eosin x250). tively lower number of tumor cells that showed moderate proliferation, localized size, and with signs of degeneration and necrosis. The neoplastic mass consisted of numerous pleomorphic neoplastic cells with a considerable number of tumor cells. Some cells showed enlarged and hyperchromatic nuclei while others lacked their nuclei or were necrotic (Figure 5A). Focal to diffuse areas of necrosis were observed between the neoplastic cells. The necrotic cells were replaced by empty cavities with focal to diffuse hemorrhage (Figure 5B).

The electron microscopic appearance of the neoplastic growth showed multiple cavitations within the cytoplasm with pyknotic nuclei that exhibited condensed chromatin. The majority of the cytoplasmic organelles were degenerated and necrotic. The mitochondriae were swollen and degenerated. Signs of lysozomal activities were observed (Figure 3C).

\section{Discussion}

The hematologic parameters showed a significant increase in total leukocytes, lymphocytes, neutrophils, and lysozyme in Groups 2 and 3 . These findings were confirmed histopathogically by activation of Kupffer's cells, active proliferation of lymphocytes in the white pulp which indicate the immunostimulating effect of both garlic and blackseed. These results are in accordance with those obtained by Nya et al.,${ }^{9}$ who recorded increased phagocytic activity and serum lysozyme activity after feeding the garlic component, allicin, for 14 days. Tousson et al., ${ }^{20}$ mentioned that the blood constituents of rabbit feed with Nigella sativa showed a significant increase in the percentages of hemoglobin, hematocrit, the mean corpuscular hemoglobin and white blood cell (WBC) counts. Majdalawieh et al.,11 reported that aqueous extract of Nigella sativa significantly enhances NK cytotoxic activity against YAC-1 tumor cells, suggesting that the documented anti-tumor effects of Nigella sativa may be, at least in part attributed to its ability to serve as a stimulant of NK anti-tumor activity. Furthermore, in vitro and in vivo studies have revealed that garlic extract stimulated immune functions, such as proliferation of lymphocyte, cytokine release, NK activity and phagocytosis. $^{21}$ Abdel-Salam and Sayed,22 reported that garlic pre-treatment of liverinjured rats induced significant amelioration in the numbers of monocytes and lymphocytes, with significant increase in granulocytes numbers. Aqueous and ethanolic extracts of garlic powder significantly stimulated proliferation of lymphocytes and an increase in IL-2 and IL4 production in vitro. ${ }^{23}$ Such immune stimulation may be one of the possible mechanisms of the anti-cancer effect of garlic and blackseed. 
The GSH was significantly increased in Group 2 while Malnoaldhyde (MDA) was the same as in Group 2 (Nigella sativa) and nonsignificant decrease in Group 3 (garlic). Avci et $a l ., 24$ reported that ingestion of garlic significantly lowered plasma and erythrocyte MDA levels and increased activities of some antioxidant enzymes that indicates that consumption of garlic decreases oxidation reactions. Attia et al. ${ }^{25}$ stated that omega 3 and NO might prevent oxidative stress and attenuate the changes in the biochemical parameters induced by gamma-HCH in male rats. El Shenawy et al.,26 reported that protection with AGE and NSO prevented most of the hematologic and biochemical changes, and markedly improved anti-oxidant capacity. It is quite possible that reduced peroxidation processes and significantly increased GSH activity may lead to the inhibition of carcinogen-induced nuclear damage by sulfides in garlic and thymoquinone in Nigella sativa. ${ }^{27,28}$

Histopathologically, the internal organs of the experimental mice of Groups 2 and 3 showed proliferation of the mononuclear phagocytic system with mild degeneration of internal organs. Our results are in agreement with those of Tousson et al.,20 who found Nigella sativa alone or combined with Thymus vulgaris are good supplements for growing rabbits without any adverse effect on histological structure of liver, kidney and testis. Similar findings were described by Salim and Fukushima, ${ }^{29}$ and Ali and Blunden, 15 who reported that administration of either Nigella sativa seed extract or its oil revealed no pathological changes in the liver, kidneys, spleen, or other organs of rats; the active proliferation of lymphocytes in the white pulp in this study agreed with our hematologic parameters.

The histopathological and electron microscopic findings in experimental mice in Group 4 , in which neoplastic mass consisted of numerous tumor cells, exhibited excessive proliferation, large size and signs of malignancy. The ultrastructural studies of the neoplastic growth showed pleomorphic cell with pleomorphic hyperchromatic nuclei that showed activated euo- and heterochromatin with cytoplasmic cavitations and organelle degeneration. Lysozyme activities were also observed. This may be attributed to Ehrlich tumor cell that may generate free radicals, disturbing the anti-oxidant status and ultimately leading to oxidative stress and carcinogenesis. ${ }^{30}$

Mice in Groups 5 and 6 revealed neoplastic mass which consisted of a comparatively lower number of tumor cells that showed moderate proliferation, localized size, and with signs of degeneration and necrosis. The electron microscopic appearance of the neoplastic growth showed multiple cavitation within the cytoplasm with pyknotic nuclei that showed condensed chromatin. Minimal pleomorphism and vaculation as compared to Group 4 were seen. These findings were similar to those obtained by Khan and Sultana, ${ }^{31}$ who recorded that Nigella sativa is a potent chemopreventive agent and suppresses Fe-NTA-induced oxidative stress, hyperproliferative response and renal carcinogenesis in Wistar rats. Garlic and its allyl sulfur may exert their protective effects on carcinogenesis in animal and in vitro by several mechanisms, including inhibition of carcinogen-induced DNA adduct formation, ${ }^{32}$ blockage of cell growth, blockage of cell proliferation, and blockage of angiogenesis, ${ }^{33}$ induction of differentiation and/or apoptosis, $, 5,34$ enhancement of carcinogen-detoxifying enzymes, 35 and/or suppression of carcinogenactivating enzymes, 36 inhibition of cyclooxygenase-2 expression, 37 scavenging carcinogeninduced free radicals, $, 38,39$ and inhibition of lipid peroxidation. ${ }^{39,40}$ Another possible mechanism of cancer prevention and suppression of cancer progression is immune enhancement by garlic, ${ }^{9}$ and Nigella sativa, ${ }^{21}$ and these agreed with our hematologic and histopathological findings.

In conclusion, it could be said that both garlic and black seed minimize the histopathological and electron microscopic alterations of ETC in mice. This may be due to an immunestimulatory effect, reduced lipid peroxidation processes, and/or enhancement of anti-oxidant action.

\section{References}

1. Gruddy SM. Recent nutrition research, implications for foods of the future. Ann Med 1991;23:187-93.

2. Benjamin HSL, Padma PT, Jeffrey MT. Allium sativum: (garlic) and cancer prevention. Int J Vitam Nutr Res 1990;10:93748.

3. Samaranayake MDP, Wickramasinghe SMN, Angunawela P, et al. Inhibition of chemically induced liver carcinogenesis in Wistar rats by garlic (Allium sativum). Phytother Res 2000;14:1-3.

4. Thapliyal R, Deshpande SS, Maru GB. Mechanism(s) of turmeric-mediated protective effects against benzopyrenederived adducts. Cancer Lett 2002:175:79-88.

5. Zhang CL, Zeng T, Zhao XL, et al. Protective effects of garlic oil on hepatocarcinoma induced by $\mathrm{N}$-nitrosodiethylamine in rats. Int J Biol Sci 2012;8:363-74.

6. Sparnins VL, Mott AW, Barany G, Wattenberg LW. Effects of allyl methyl trisulfide on glutathione S-transferase activity and BP-induced neoplasia in the mouse. Nutr Cancer 1986;8:211-5.

7. Nishino H, Iwashima A, Itakura Y, et al. Antitumorpromoting activity of garlic extracts. Oncology 1989;46:277-80.

8. Wattenberg LW, Sparnins VL, Barany G. Inhibition of $\mathrm{N}$-nitrosodiethylamine carcinogenesis in mice by naturally occurring organosulfur compounds and monoterpenes. Cancer Res 1989;49:2689-92.

9. Nya EJ, Dawood Z, Austin B. The garlic component, allicin, prevents disease caused by Aeromonas hydrophila in rainbow trout, Oncorhynchus mykiss (Walbaum). J Fish Dis 2010;33:293-300.

10. Nadkarni K. Crocus sativus, Nigella sativa. In: Nadkarni KM, ed. Indian materia medica. Bombay, Popular Prakashan: 1976. pp 386-411.

11. Majdalawieh AF, Hmaidan R, Carr RI. Nigella sativa modulates splenocyte proliferation, Th1/Th2 cytokine profile, macrophage function and NK anti-tumor activity. J Ethnopharmacol 2010;131:26875 .

12. Al-Hader A, Aqel M, Hassan Z. Hypoglycaemic effects of the volatile oil of Nigella sativa. Int $\mathrm{J}$ Pharmacognosy 1993;31:96-100.

13. El Tahir KE, Ashour MM, Al-Harbi MM. The cardiovascular actions of the volatile oil of the black seed (Nigella sativa) in rats: elucidation of the mechanism of action. Gen Pharmacol 1993;24:1123-31.

14. El-Alfy T, El-Fatatry H, Toama M. Isolation and structure assignment of an antimicrobial principle from the volatile oil Nigella sativa L. Pharmazia 1975;30:10911.

15. Ali BH, Blunden G. Pharmacological and toxicological properties of Nigella sativa. Phytother Res 2003;17:299-305.

16. Feldman BF, Zinkl JG, Jain VC. Schalm's veterinary hematology. 5th ed. Philadelphia: Lippincott Williams and Wilkins; 2000. pp 1145-1146.

17. Bancroft TD, Stevens A, Turner DR. Theory and practice of histological technique. 4 th edition. New York: Churchill Livingston; 1996.

18. Weakly B. A Beginner's handbook in biological transmission electron microscopy. London: Churchill Livingston; 1981.

19. SAS Institute. SAS Statistical guide for personal computers. 6th ed. Cary: SAS Institute; 2003.

20. Tousson E, El-Moghazy M, El-Atrsh E. The possible effect of diets containing Nigella sativa and Thymus vulgaris on blood parameters and some organs structure in rabbit. Toxicol Ind Health 2011;27:107-16.

21. Sumiyoshi H. [New pharmacological activities of garlic and its constituents]. Nihon Yakurigaku Zasshi 1997;110:93-7. [Article in Japanese].

22. Abdel-Salam BK, Sayed AA. Beneficial effect of garlic on D-galactosamine and lipopolysaccharide-induced acute hepatic 
failure in male albino rats. Allergol Immunopathol (Madr) 2012;40:238-43.

23. Colić M, Savić M. Garlic extracts stimulate proliferation of rat lymphocytes in vitro by increasing IL-2 and IL-4 production. Immunopharmacol Immunotoxicol 2000;22:163-81.

24. Avci A, Atli T, Ergüder IB, et al. Effects of garlic consumption on plasma and erythrocyte antioxidant parameters in elderly subjects. Gerontology 2008;54:173-6.

25. Attia AM, El-Banna SG, Nomeir FR, Abd ElBasser MI. Lindane-induced biochemical perturbations in rat serum and attenuation by omega- 3 and Nigella sativa seed oil. Indian J Biochem Biophys 2011;48: 184-90.

26. El Shenawy NS, Soliman MF, Reyad SI. The effect of antioxidant properties of aqueous garlic extract and Nigella sativa as antischistosomiasis agents in mice. Rev Inst Med Trop Sao Paulo 2008;50:29-36.

27. Wargovich MJ, Goldberg MT. Diallyl sulfide. A naturally occurring thioether that inhibits carcinogen-induced nuclear damage to colon epithelial cells in vivo. Mutat Res 1985;143:127-9.

28. Harzallah HJ, Grayaa R, Kharoubi W, et al. Thymoquinone, the Nigella sativa bioactive compound, prevents circulatory oxidative stress caused by 1,2-dimethylhy- drazine in erythrocyte during colon postinitiation carcinogenesis. Oxid Med Cell Longev 2012;2012:854065.

29. Salim EI, Fukushima S. Chemopreventive potential of volatile oil from black cumin (Nigella sativa L.) seeds against rat colon carcinogenesis. Nutr Cancer 2003;45:195202.

30. Mandal D, Lahiry L, Bhattacharyya A, et al. Black tea protects thymocytes in tumorbearing animals by differential regulation of intracellular ROS in tumor cells and thymocytes. J Environ Pathol Toxicol Oncol 2005;24:91-104.

31. Khan N, Sultana S. Inhibition of two stage renal carcinogenesis, oxidative damage and hyperproliferative response by Nigella sativa. Eur J Cancer Prev 2005;14:159-68.

32. Amagase HSE, Milner JA. Dietary components modify the ability of garlic to suppress 7,12-dimethylbenz(a)anthaceneinduced mammary DNA adducts. J Nutr 1996;126:817-24.

33. Matsuura N, Miyamae Y, Yamane K, et al. Aged garlic extract inhibits angiogenesis and proliferation of colorectal carcinoma cells. J Nutr 2006;136:S842-6.

34. Oommen S, Anto RJ, Srinivas G, Karunagaran D. Allicin (from garlic) induces caspase-mediated apoptosis in cancer cells. Eur J Pharmacol 2004;485:97-
103.

35. Kirlin WG, Cai J, DeLong MJ, et al. Dietary compounds that induce cancer preventive phase 2 enzymes activate apoptosis at comparable doses in HT29 colon carcinoma cells. J Nutr 1999;129:1827-35.

36. Chung JG, Lu HF, Yeh CC, et al. Inhibition of $\mathrm{N}$-acetyltransferase activity and gene expression in human colon cancer cell lines by diallyl sulfide. Food Chem Toxicol 2004;42:195-202.

37. Sengupta A, Ghosh S, Das S. Modulatory influence of garlic and tomato on cyclooxygenase-2 activity, cell proliferation and apoptosis during azoxymethane induced colon carcinogenesis in rat. Cancer Lett 2004;208:127-36.

38. Wu X, Kassie F, Mersch-Sundermann V. Induction of apoptosis in tumor cells by naturally occurring sulfur-containing compounds. Mutat Res 2005;589:81-102.

39. Shaarawy SM, Tohamy AA, Elgendy SM, et al. Protective effects of garlic and silymarin on NDEA-induced rats hepatotoxicity. Int J Biol Sci 2009;5:549-57.

40. Sengupta A, Das S. Tomato and garlic can modulate azoxymethaneinduced colon carcinogenesis in rats. Eur $\mathrm{J}$ Cancer Prev 2003;12:195-200. 